\title{
Medical Negligence : An Overview
}

\author{
Bratin Kumar Dey ${ }^{1}$
}

\section{ABSTRACT}

Medical professionals are treated as next to God. They provide humanitarian services and gives solace to individuals suffering from various diseases and disorders. Due to their great service to humanity, the doctors and medical professionals are treated with reverence and since the ancient times the medical profession has been considered as a noble profession. However with the passage of time, there has been a change in the doctor - patient relationship.

During the last few decades, a number of incidents have come to light in which the patients have suffered due to the error and inadvertent conduct of doctors. Due to the increasing conflicts and legal disputes between the doctors and patients, most of the legal systems have developed various rules and principles to deal with such inadvertent behavior of doctors. This has led to the development of a new branch of jurisprudence, i.e. medical negligence. Hence, any negligence on part of the medical professional would be treated as either a tort of negligence or a deficiency in service under Consumer Protection Act, 1986. As the profession involves the idea of an occupation requiring purely intellectual skills or of manual skills controlled by the intellectual skill of the operator, it is distinctively different from an occupation, which is substantially production or sale or arrangement for the production or sale of commodities. Medicine is a highly complex domain.

It is difficult for consumer laws to review medical negligence cases with flawless technical clarity and accuracy. Thus medical negligence is not purely a matter of consideration for judiciary but also the technical inputs of specialized experts in the field have substantial weightage while deciding the case of medical negligence against doctors. The present paper is devoted to introvert inspection of negligence in medical profession in the light of existing laws with more emphasis on the interpretation of consumer protection law by judiciary.

Kevwords:

Medical Negligence; Malpractice; Liability, Legal; Malpractice

$\mathrm{M}$ edical professionals are treated as next to God. They provide humanitarian services and gives solace to individuals suffering from various diseases and disorders. Due to their great service to humanity, the doctors and medical professionals are treated with reverence and since the ancient times the medical profession has been considered as a noble profession. However with the passage of time, there has been a change in the doctor - patient relationship. During the last few decades a number of incidents have come to light in which the patients have suffered due to the error and inadvertent conduct of doctors. Due to the increasing conflicts and legal disputes between the doctors and patients, most of the legal systems have developed various rules and principles to deal with such inadvertent behavior of doctors. This has led to

1 - Advocate, High Court Calcutta.

\section{Corresponding author:}

Bratin Kumar Dey

email: bratin.world@gmail.com the development of a new branch of jurisprudence, i.e. medical negligence. Hence, any negligence on part of the medical professional would be treated as either a tort of negligence or a deficiency in service under Consumer Protection Act, 1986. As the profession involves the idea of an occupation requiring purely intellectual skills or of manual skills controlled by the intellectual skill of the operator, it is distinctively different from an occupation, which is substantially production or sale or arrangement for the production or sale of commodities. Medicine is a highly complex domain. It is difficult for consumer laws to review medical negligence cases with flawless technical clarity and accuracy. Thus medical negligence is not purely a matter of consideration for judiciary but also the technical inputs of specialized experts in the field have substantial weightage while deciding the case of medical negligence against doctors. The present paper is devoted to introvert inspection of negligence in medical profession in the light of existing laws with more emphasis on the interpretation of consumer protection law by judiciary. 
In the Sanskrit there is famous thought i.e. 'Aarogyam Dhanasampada', which implies 'Health is Wealth', and we all are very cautious about it to some extent. Happiness and health have very close relation, just like sound mind needs a sound body. We try our level best to be fit and healthy. But, sometimes fortunately or unfortunately we get some problems to our health, wherein we needed to take help from doctors. Doctor is considered as a highly responsible person because he can save a life of human being, when the patient is in a critical condition. He has the highest responsibilities over the life of the patient. Since no man is perfect in this world, it is evident that a person who is skilled and has knowledge over a particular subject can also commit mistakes during his practice. Such mistakes in the medical profession may lead to minor injuries or some serious kinds of injuries and sometimes such mistakes may even cause death. Such situations call for a need for remedies to the injured people so that justice is upheld and this gave rise to the concept of medical negligence.

Negligence, in simple terms, is the failure to take due care and caution. It is a breach of a duty caused by the omission to do something, which a reasonable person guided by those considerations which ordinarily regulate the conduct of human affairs, should have done. It may also be doing something, which a prudent and reasonable person would not have done. The essential components of negligence are: 'duty', 'breach' and 'resulting damage'. These definitions are rather relative and can change with the circumstances. When trying to drag a person away from the clutches of an attacking animal, one cannot ask whether this would cause damage to the person's limbs. Doctors can also be faced with similar contingencies. On finding an accident victim in a dangerous condition, a doctor may have to attempt a crude form of emergency surgery to try and save the person's life. No negligence is involved in such cases.

Initially court could not show much interest in such medical negligence matters. But as the time passed and numbers of such incidence increased drastically, judiciary has paid special attention towards it and it is evident from the number of judgments that, they have played crucial role in developing the concept of medical negligence and provided remedies to the patients. Allegation of malpractices and lack infrastructure in public hospitals have increased, while private service providers have been accused of profiteering and the exploitative practices. Weak regulation regime came in the way of redressal of grievances, most importantly such negligence matters are being verified by fellow doctors who hardly ever support the patient. There are many landmark decisions delivered by the judiciary such as Indian Medical Association case, Achutrao Haribhau Khodwa case, Jacob Mathew case, Anuradha Saha case etc. wherein court considered the various aspects of medical negligence to provide the remedy by imposing tortious, civil and criminal liability.

Medical negligence is the failure of a medical practitioner to provide proper care and attention and exercise those skills which a prudent, qualified person would do under similar circumstances. It is a commission or omission of an act by a medical professional which deviates from the accepted standards of practice of the medical community, leading to an injury to the patient. It may be defined as a lack of reasonable care and skill on the part of a medical professional with respect to the patient, be it his history taking, clinical examination, investigation, diagnosis, and treatment that has resulted in injury, death, or an unfavorable outcome. Failure to act in accordance with the medical standards in vogue and failure to exercise due care and diligence are generally deemed to constitute medical negligence.

Everyone is responsible, not only for the result of his or her willful acts, but also for an injury occasioned to another by his or her want of ordinary care or skill in the management of his or her property or person. Negligence is not the act itself, but the fact which defines the character of the act, and makes it a legal wrong. In common law, negligence is a complex relationship, a space, more than a 'thing': a shifting, malleable, interaction between time and place and, to varying degrees, society, law, ethics, and professionals. The elements of a cause of action in tort of negligence are: (1) a duty to use ordinary care; (2) breach of that duty; (3) approximate causal connection between the negligent conduct and the resulting injury and (4) resulting damage. Negligence as a tort is the breach of a legal duty to take care, which results in damage undesired by the defendant, to the plaintiff. 
In essence, negligence consists of failure to take reasonable precautions against risks of injury to others, which one ought to have foreseen and guarded against. Negligence involves behaving in a manner that lacks the legality of protecting other people against foreseeable risks. It is a Tort. Tort is a civil wrong committed by one person on another. The word 'Person' is the important issue in negligence. Fictional persons cannot be negligent though they may be held liable vicariously. In a negligence lawsuit the tortfeasor who committed the wrong is a person. Negligence in law is the failure to meet a standard of behavior established to protect society against unreasonable risk. It is the cornerstone of tort liability and a key factor in most personal injury and property's damage trials. The doctrine of negligence does not require the elimination of all risk from a person's conduct, only all unreasonable risk, are required to be eliminated, which is measured by the seriousness of possible consequences. Thus, a higher standard applies to nitroglycerin manufacturers than to those making kitchen matches. In certain critical fields, e.g. the milk industry, the law imposes liability for every mistake, even when the strictest precautions are taken, a policy known as strict liability. Car accidents are a common source of legal liability. In almost all accidents, someone will be found responsible for failing to act as they should. Most accidents result in damage to the vehicles or injury to people in them, and these are clearly a direct result of the accident. Negligence excludes wrongful intention since they are mutually exclusive. Carelessness is not culpable or a ground for legal liability except in those cases in which the law has imposed the duty of carefulness. Negligence may be in action or in omission.

Negligence is the omission to do something which a reasonable man, guided upon those considerations which ordinarily regulate the conduct of human affairs, would do, or doing something which a prudent and reasonable man would not do. The defendants might have been liable for negligence, if, unintentionally, they omitted to do that which a reasonable person would have done, or did that which a person taking reasonable precautions would not have done. A reasonable man would act with reference to the average circumstances of the temperature in ordinary years. The defendants had provided against such frosts as experience would have led men, acting prudently, to provide against; and they are not guilty of negligence, because their precautions proved insufficient against the effects of the extreme severity of the frost of 1856 , which penetrated to a greater depth than any which ordinarily occurs south of the polar regions. Such a state of circumstances constitutes a contingency against which no reasonable man can provide. The result was an accident, for which the defendants cannot be held liable.

Supreme Court in its judgment simplified negligence as the breach of a legal duty to care. It means carelessness in a matter in which the law mandates carefulness. A breach of this duty gives a patient the right to initiate action against negligence.

The Hon'ble Apex Court admits that no human being is perfect and even the most renowned specialist could make a mistake in detecting or diagnosing the true nature of a disease. The law expects a duly qualified physician to use that degree of skill and care which an average man of his qualifications ought to have and does not expect him to bring the highest possible degree of skill in the treatment of his patients, or to be able to guarantee cure.

Thus as reflected from the various decisions of Supreme Court a doctor can be held liable for negligence only if -

1) One can prove that she/ he is guilty of a failure to act with ordinary skills and fail to act with reasonable care. ${ }^{1}$

2) An error of judgment constitutes negligence only if a reasonably competent professional with the standard skills that the defendant professes to have, and acting with ordinary care, would not have made the same error. ${ }^{1}$

3) The principle of res ipsa loquitur comes into operation only when there is proof that the occurrence was unexpected, that the accident could not have happened without negligence and lapses on the part of the doctor, and that the circumstances conclusively show that the doctor and not any other person was negligent. ${ }^{1}$

4) A doctor can be held to be negligent only if the complainant can prove that the standard of medical care given does not match the standards of care set up by the 
profession itself. It says a wrong outcome or recourse to one of several different methods available to treat a patient cannot be termed as negligence. ${ }^{2}$

5) A simple lack of care, an error of judgment or an accident, even fatal, will not constitute culpable medical negligence. If the doctor had followed a practice acceptable to the medical profession at the relevant time, he or she cannot be held liable for negligence merely because a better alternative course or method of treatment was also available, or simply because a more skilled doctor would not have chosen to follow or resort to that practice. Professionals may certainly be held liable for negligence if they were not possessed of the requisite skill which they claimed, or if they did not exercise, with reasonable competence, the skill which they did possess. ${ }^{3}$

In legal sense medical negligence is a subset of professional negligence which is a branch of the general concept of negligence that applies to the situation in which physician who represented himself or herself having special knowledge and art, breaches his or her duty to take care about his or her patient. The general rules apply in establishing that the physician who owed the duty of care is in breach of that duty. Once the physician has accepted to treat the patient, the legal relationship between physician and patient is created, this means a medical relationship is established and this relationship resulted in duty to take care. The base of this legal relationship is the rule of 'reasonable reliance' by the claimant on the skills of the doctor. Dealing with the question of duty to take care, the court observed :

"Where a person is so placed that others could reasonably rely upon his judgment or his skill or upon his ability to make careful inquiry, and a person takes it upon himself to give information or advice to, or allows his information or advice to be passed on to, another person who, as he knows or should know, will place reliance upon it, then a duty of care will arise."

Under the Section 2(1)(o) of The Consumer Protection Act, 1986, the following categories of doctors/hospitals included under this Section and as interpreted by judiciary in different awards:

(i) All medical/dental practitioners doing independent medical/dental practice unless rendering only free service.

(ii) Private hospitals charging all patients.

(iii) All hospitals having free as well as paying patients and all the paying and free category patients receiving treatment in such hospitals.

(iv) Medical/dental practitioners and hospitals paid by an insurance firm for the treatment of a client or an employment for that of an employee. It exempts only those hospitals and the medical/ dental practitioners of such hospitals which offer free service to all patients. ${ }^{4}$

(v) A patient treated free of cost in a charity or other hospital will still be a consumer as per the Consumer Protection Act if the person buys medicines from the nursing home's pharmacy, the national consumer forum has ruled. ${ }^{5}$

(vi) Persons who availed themselves of the facility of medical treatment in a Government Hospital are not 'consumers' as defined in Consumer Protection Act and the said facility cannot be regarded as service "hired" for "consideration. ${ }^{6}$

(vii) It was contended that direct and indirect taxes paid to the State by a citizen constituted 'consideration' for the services and facility provided to a citizen by the State. The National Commission, making a distinction between 'tax' and 'fee' held that a tax is levied as part of common burden while fee is for payment of specific benefit or privilege. Unlike 'fee', 'tax' in its true nature is a levy made by the state for the general purposes of the Government and it cannot be regarded as payment for any particular or specific service. ${ }^{6}$

(viii) On the question whether contributors to the CGHS Scheme and patients in a 'paying ward' in a Government Hospital are 'consumers' within the meaning of the Act, it observed that contribution to CGHS should be taken to be in lieu of free treatment in the diverse dispensaries, as well as the free provisions of medicines from these dispensaries. In regard to 'paying wards', it further observed that these payments are specifically related to special rooms/beds for which the separate charge is made; the (free) medical facilities are common to all patients, inclusive of those in the paying wards, without discrimination. ${ }^{6}$

The famous Bolam principle states that a doctor cannot be held liable when he acted as any other 
established and responsible medical man would act. ${ }^{7}$ In a Jacob Matthews v State of Punjab, ${ }^{8}$ the Hon'ble Supreme Court framed guidelines are as mentioned under :

I. A complaint against a doctor is not to be entertained unless the allegation against him is supported by a credible opinion given by another doctor. If the doctor feels that negligence on the part of the medical practitioner has resulted to the loss of well being of the plaintiff, then the complaint may be registered.

II. The investigating officer before proceeding against the accused ought to get a medical opinion from a competent doctor, preferably in the government services, qualified in that field of medical sciences who can give an impartial opinion.

III. The arrest of the accused should be withheld unless it is believed by the investigating officer unless he believes that it is necessary to arrest the accused so as to further the investigation of the case. It may further be withheld unless it is believed that the accused doctor will not make himself available to face the prosecution unless he is arrested.

As far as judiciary is concerned, it has considered various aspects of medical negligence and widened the meaning of it. In the very landmark judgment Indian Medical Association ${ }^{9}$ case the supreme court defined the parameters of rights and obligations of professionals of allopathic and homeopathic systems of medicine and ruled that the Consumer Protection Act, 1986 is applicable to persons engaged in medical profession either as a private practitioner or as a Government doctor working in hospitals or Government dispensaries. It is further held that a patient who is a consumer within the meaning of the CP Act 1986, has to be awarded compensation for loss or injury suffered by him due to negligence of the doctor by applying the same tests are applied inaction for damages for negligence in law of torts. In the present case the issues before the court were, in what circumstances a medical practitioner can be regarded as rendering 'service' as per the definition given under CP Act 1986 and another issue was if the service rendered at a hospital or nursing home can it be comes under the definition of 'service' of CP Act 1986. The Supreme Court mentioned that medical service is treated as in ambit of 'services'. It is not contract of personal service as there is absence of master servant relationship. Further if the medical service is rendered free of charge are not in the purview of 'service'. On the other hand if such medical service is rendered by independent doctors free of charge are under the definition of service. Furthermore, medical service if rendered against payment of consideration is in the scope of the Consumer Protection Act, 1986. In addition to this court also mentioned that a medical service where payment of consideration is paid by third party is treated as in the ambit of the CP Act and also hospital in which some person are charged and some are exempted from charging because of their inability of affording such services will be treated as 'consumer' under the Consumer Protection Act, 1986. In another significant judgement the Supreme Court enlarged the ambit of vicarious liability and extended the reach of Consumer Protection Act, 1986. Chandrikabai, a teacher died on July 24, 1963 as the doctors had left a mop (towel) in her abdomen a sterilization operation in Aurangabad's Government hospital on July 10, 1963, where she was admitted for delivery. Court further mentioned that running a hospital could be a welfare activity by the Government but not sovereign function. Apex court held that once the death by negligence is established the doctrine of res ipsa loquitor i.e. things speaks for itself was held applicable in a case like this and the state as an employer would be liable to pay damages for negligence of the doctor. Theory of sovereign immunity has no application in such cases.

Negligence in the context of the medical profession necessarily calls for a treatment with a difference. To infer rashness or negligence on the part of a professional, in particular a doctor, additional considerations apply. A case of occupational negligence is different from one of professional negligence. A simple lack of care, an error of judgment or an accident, is not proof of negligence on the part of a medical professional. So long as a doctor follows a practice acceptable to the medical profession of that day, he cannot be held liable for negligence merely because a better alternative course or method of treatment was also available or simply because a more skilled doctor would not have chosen to follow or resort to that practice or procedure which the accused 
followed.

When it comes to the failure of taking precautions, what has to be seen is whether those precautions were taken which the ordinary experience of men has found to be sufficient; a failure to use special or extraordinary precautions which might have prevented the particular happening cannot be the standard for judging the alleged negligence. So also, the standard of care, while assessing the practice as adopted, is judged in the light of knowledge available at the time of the incident, and not at the date of trial. Similarly, when the charge of negligence arises out of failure to use some particular equipment, the charge would fail if the equipment was not generally available at that particular time, at which it is suggested it should have been used.

The Hon'ble Supreme Court in Laxman v. Trimbak, ${ }^{10}$ held:

"The duties which a doctor owes to his patient are clear. A person who holds himself out ready to give medical advice and treatment impliedly undertakes that he is possessed of skill and knowledge for the purpose. Such a person when consulted by a patient owes him certain duties viz., a duty of care in deciding whether to undertake the case, a duty of care in deciding what treatment to give or a duty of care in the administration of that treatment. A breach of any of those duties gives a right of action for negligence to the patient. The practitioner must bring to his task a reasonable degree of skill and knowledge and must exercise a reasonable degree of care. Neither the very highest nor very low degree of care and competence judged in the light of the particular circumstances of each case is what the law requires."

In Achutrao Haribhau Khodwa v. State of Maharashtra, ${ }^{11}$ the Supreme Court said:

The skill of medical practitioners differs from doctor to doctor. The very nature of the profession is such that there may be more than one course of treatment which may be advisable for treating a patient. Courts would indeed be slow in attributing negligence on the part of a doctor if he has performed his duties to the best of his ability and with due care and caution. Medical opinion may differ with regard to the course of action to be taken by a doctor treating a patient, but as long as a doctor acts in a manner which is acceptable to the medical profession and the Court finds that he has attended on the patient with due care skill and diligence and if the patient still does not survive or suffers a permanent ailment, it would be difficult to hold the doctor to be guilty of negligence.

In a case Apex Court in Spring Meadows Hospital v. Harjol Ahluwalia, ${ }^{12}$ has specifically laid down the following principles for holding doctors negligent:

"Gross medical mistake will always result in a finding of negligence. Use of wrong drug or wrong gas during the course of an anesthetic will frequently lead to the imposition of liability and in some situations even the principle of res ipsa loquitur can be applied. Even delegation of responsibility to another may amount to negligence in certain circumstances. A consultant could be negligent where he delegates the responsibility to his junior with the knowledge that the junior was incapable of performing of his duties properly. We are indicating these principles since in the case in hand certain arguments had been advanced in this regard, which will be dealt with while answering the question posed by us."

Recently Justice S.B.Sinha in Malay Kumar Ganguly v. Dr. Sukumar Mukherjee ${ }^{13}$ case has preferred Bolitho test to Bolam test. The Supreme Court redefined medical negligence saying that the quality of care to be expected of a medical establishment should be in tune with and directly proportional to its reputation. The Court extended the ambit of medical negligence cases to include overdose of medicines, not informing patients about the side effects of drugs, not taking extra care in case of diseases having high mortality rate and hospitals not providing fundamental amenities to the patient. The decision also says that the court should take into account patient's legitimate expectations from the hospital or the concerned specialist doctor.

In V. Kishan Rao v. Nikhil Super Speciality Hospital, ${ }^{14}$ the Hon'ble Supreme Court expressed the opinion that Bolam test needs to be reconsidered in India in view of Article 21, which guarantees right to medical treatment and care. However, the Court expressed its inability because of the binding precedent of Jacob Mathew, which approved the test.

In Kusum Sharma v. Batra Hospital and Medical 
Research Centre,$^{15}$ the Hon'ble apex court reiterated the legal position after taking survey of catena of case law. In the context of issue pertaining to criminal liability of a medical practitioner, Hon'ble Mr. Justice Dalveer Bhandari speaking for the Bench, laid down that the prosecution of a medical practitioner would be liable to be quashed if the evidence on record does not project substratum enough to infer gross or excessive degree of negligence on his/her part.

In Vinitha Ashok v. Lakshmi Hospital, ${ }^{16}$ removal of pregnancy was done without ultrasonography and uterus of the patient had to be removed. There was expert evidence to indicate that ultrasonography would not have established ectopic pregnancy but some text books indicated otherwise. The general practice in the area in which the doctor practiced was not to have ultrasonography done. Therefore no negligence was attributed on this ground even if two views could be possible.

In Dr. P.N. Rao v. G. Jayaprakasu, a very promising young boy of 17 was admitted in a government hospital for removal of tonsils. As a result of the negligence in the administration of anaesthesia during the operation, the patient became victim of cerebral anoxia making him dependant on his parents. The anesthetist, the surgeon and the government were all held liable for damages to the plaintiff

In Nizam's Institute of Medical Sciences v. Prasanth S. Dhananka, ${ }^{17}$ the complainant who was then an engineering student suffered from recurring fever. The $\mathrm{X}$ ray examination revealed a tumour in left hemithorax with erosion of ribs and vertebra. Even then without having MRI or Myelography done, cardiothoracic surgeon excised the tumour and found vertebral body eroded. Operation resulted in acute paraplegia of the complainant. MRI or Myelography at the pre-operation stage would have shown necessity of a nuerosurgeon at the time of operation and the paraplegia perhaps avoided. Consent was not taken for removal of tumour but only for excision biopsy. The hospital and the surgeon were held liable for negligence.

In Dr. Balram Prasad and others v. Dr. Kunal Saha and another, ${ }^{18}$ Hon'ble Justice V. Gopala Gowda, and Hon'ble Justice C. K. Prasad, were pleased to pass an award of adequate and just compensation was finally decided by the Supreme Court on October 24, 2013, and it awarded a little more than Rs. 6 crores plus interest , which has been so far the highest compensation ever awarded by any court in India for medical negligence. Though the lawyers for the hospital and the doctors argued that the multiplier method should have been used for calculating compensation, the Supreme Court was clearly of the view that the method was not suitable for determining the quantum of compensation for medical negligence. The Hon'ble Supreme Court rejected the multiplier method in this case and provided an illustration to show how useless the method can be for medical negligence cases. The court wrote:

"The multiplier method was provided for convenience and speedy disposal of no fault motor accident cases. Therefore, obviously, a 'no fault' motor vehicle accident should not be compared with the case of death from medical negligence under any condition. The aforesaid approach in adopting the multiplier method to determine the just compensation would be damaging for society for the reason that the rules for using the multiplier method to the notional income of only Rs. 15,000/- per year would be taken as a multiplicand. In case, the victim has no income then a multiplier of 18 is the highest multiplier used under the provision of Ss. $163 \mathrm{~A}$ of the Motor Vehicles Act read with the Second Schedule.... Therefore, if a child, housewife or other non-working person fall victim to reckless medical treatment by wayward doctors, the maximum pecuniary damages that the unfortunate victim may collect would be only Rs.1.8 lakh. It is stated in view of the aforesaid reasons that in today's India, Hospitals, Nursing Homes and doctors make lakhs and crores of rupees on a regular basis. Under such scenario, allowing the multiplier method to be used to determine compensation in medical negligence cases would not have any deterrent effect on them for their medical negligence but in contrast, this would encourage more incidents of medical negligence in India bringing even greater danger for the society at large."

Thus, a doctor who is charged with negligence can absolve himself from liability if he can prove that he acted in accordance with the general and approved practice. He will be held liable only if the judgment is 
so palpably wrong as to imply an absence of reasonable skill and care on his part.

The rules as to the duty of care in medical negligence cases are the same as the rules applicable to all other kinds of negligence. Common law recognizes four basic levels of fault: negligence, recklessness or wanton conduct, intentional misconduct, and strict liability (irrespective of fault). Negligence generally means careless or inadvertent conduct that results in harm or damage. It is a recurring factor in an aggregate majority of accidental damages. It encompasses both active and passive forms of fault. That is to say, failing or omitting to do something may result in liability just as much as actively doing something wrong. Reckless or wanton conduct generally refers to a willful disregard for whether harm may result and or a disregard for the safety and welfare of others. Strict liability may be imposed, even in the absence of fault, for accidents involving certain defective products or extra hazardous activities. In common law duty is the base of liability of a person to be punished, forced to compensate, or otherwise subjected to a sanction by the law. There are many grounds on which responsibility may be imposed, and others may be invented in the future, but those which have featured in legal systems up to now can be classified according to three criteria.

The first is the conduct of the person held responsible: is he responsible on account of his conduct, or is he held responsible irrespective of his conduct?

The second is causal connection. When a person is to be held responsible for harm, must it be shown that his conduct caused the harm? Or is it sufficient that he occasioned it, e.g. by providing an opportunity for the harm to be done? Or can he be held responsible in the absence of any such connection?

The third is fault. Can a person be held responsible only when he is shown to have been at fault or can he be held responsible even in the absence of fault, i.e. on the basis of strict liability?

Under civil law, at a point where the Consumer Protection Act ends, the law of torts takes over and protects the interests of patients. This applies even if medical professional provide free service. In cases where the services offered by the doctor or hospital do not fall in the ambit of 'service' as defined in the consumer Protection Act, patients can take recourse to the law relating to negligence under the law of torts and successfully claim compensation. The onus is on the patient to prove that the doctor was negligent and that the injury was a consequence of the doctor's negligence. Such cases of negligence may include transfusion of blood of incorrect blood groups, leaving a mop in the patient's abdomen after operating, unsuccessful sterilization resulting in the birth of a child, removal of organs without taking consent, operating on a patient without giving anesthesia, administering wrong medicine resulting in injury, etc

The Medical Negligence is a very hot topic nowa days in the Consumer Courts. The Profession of Medicine is getting worst with regards to the Supreme Court's decision and the whole aspect is turning its way to criminal prosecution which may hamper the prestige of medical profession. In recent time the cost of the medi-care has gone up enormously and beyond the reach of common man, the so-called cut-throat competition among the hospitals, notwithstanding. District and general hospitals have inadequate supply of medicines and medical equipment and the doctors there are working with no incentives. Provision of medical facilities through Government should be raised to a higher level by increasing the budget provisions for strengthening the government hospitals with equal facilities. Motive is something, which prompts a man to form an intention, and for the same the doctors must get an advantage as defense, because his major intention is saving life of the people. The doctors should also be more careful to perform their duties. Gross lack of competency or gross inattention, or indifference to the patient's safety can only initiate a proceeding against a doctor. A healthy medical environment can create a great society. Hence there should be a sense of responsibility in doctors as well as consumers regarding the standard care and knowledge (Doctor's) and regarding marinating the respect and prestige of doctor who save the life of human and are the sole base of saving humanity(Consumer's). Finally, most importantly the doctors individually and collectively shall introspect their style of functioning and make sincere attempt to strengthen doctor-patient relationship and strive to put forth in their best possible 
care and skill and competence.

\section{References}

1. Article, Medical Negligence and the law, K K S R Murthy, Indian Journal of Medical Ethics, July - September 2007; IV(3) : [116,117]

2. http://www.dnaindia.com/mumbai/report_court-has-killed-allmedical negligence-cases_1350940 court has killed all medical negligence cases Published : Monday, Feb 22, 2010: 0: 12IST By MS Kamath I Place : Mumbai Agency : DNA

3. Indian Journal of Medical Ethics 2005 Oct-Dec 2; 4. Supreme Court Judgment on criminal Medical Negligence : a challenge to the profession, MR Hariharan Nair.

4. http://www.medindia.net/doctors/cpa/case-1-9.asp, landmark case, Dr. K. Mathiharan (Consultant Legal Medicine) Institute of Legal Medicine 53/27, 5th Street, Padmanabha Nagar, Adayar, Chennai - 600020 .

5. 5.http://www.financialexpress.com/news/charityhospital-death-patient-still-a-consumer-must-get- compensation/746170/1to4, Charity hospital death ? Patient still a consumer, must get compensation, Agencies, Posted : Friday, Feb 04, 2011; at 1504 hrs IST.

6. http://www.heathlibrary.com/book9_chapter542.htm Medical profession and consumer protection act by Dr. Jagdish Singh.

7. Bolam Vs. Friern Hospital Management Committee [(1957) 2 All ER 118 (QBD)]

8. AIR 2005 Crl. L.J. 3710

9. Indian Medical Association Vs. VP Shantha [AIR 1996 SC 550]

10. Dr. Laxman Balkrishna Joshi Vs. Dr. Trimbak Bapu Godbole \& Another [(1969) 1 SCR 206]

11. AIR 1996 (2) SCC 634

12. AIR 1998 SC 1801

13. AIR 2010 SC 1162

14. AIR 2010 (2) UAD 331

15. AIR 2010 SC 1050

16. AIR $2001 \mathrm{SC} 3914$

17. AIR 20096 SCC 1

18. AIR 20137 Supreme 323 